\title{
Protective effects of extracts from Pomegranate peels and seeds on liver fibrosis induced by carbon tetrachloride in rats
}

\author{
Xiang-lan Wei ${ }^{1,2}$, Ru-tang Fang ${ }^{3}$, Yong-hua Yang ${ }^{4}$, Xue-yuan Bi ${ }^{1}$, Guo-xia Ren ${ }^{2}$, A-li Luo ${ }^{2}$, Ming Zhao ${ }^{*}$ and \\ Wei-jin Zang ${ }^{1 *}$
}

\begin{abstract}
Background: Liver fibrosis is a feature in the majority of chronic liver diseases and oxidative stress is considered to be its main pathogenic mechanism. Antioxidants including vitamin $\mathrm{E}$, are effective in preventing liver fibrogenesis. Several plant-drived antioxidants, such as silymarin, baicalin, beicalein, quercetin, apigenin, were shown to interfere with liver fibrogenesis. The antioxidans above are polyphenols, flavonoids or structurally related compounds which are the main chemical components of Pomegranate peels and seeds, and the antioxidant activity of Pomegranate peels and seeds have been verified. Here we investigated whether the extracts of pomegranate peels (EPP) and seeds (EPS) have preventive efficacy on liver fibrosis induced by carbon tetrachloride $\left(\mathrm{CCl}_{4}\right)$ in rats and explored its possible mechanisms.

Methods: The animal model was established by injection with $50 \% \mathrm{CCl}_{4}$ subcutaneously in male wistar rats twice a week for four weeks. Meanwhile, EPP and EPS were administered orally every day for 4 weeks, respectively. The protective effects of EPP and EPS on biochemical metabolic parameters, liver function, oxidative markers, activities of antioxidant enzymes and liver fibrosis were determined in $\mathrm{CCl}_{4}$-induced liver toxicity in rats.

Results: Compared with the sham group, the liver function was worse in $\mathrm{CCl}_{4}$ group, manifested as increased levels of serum alanine aminotransferase, aspartate aminotransferase and total bilirubin. EPP and EPS treatment significantly ameliorated these effects of $\mathrm{CCl}_{4}$. EPP and EPS attenuated $\mathrm{CCl}_{4}$-induced increase in the levels of TGF- $\beta 1$, hydroxyproline, hyaluronic acid laminin and procollagen type III. They also restored the decreased superoxide dismutase (SOD), glutathione peroxidase (GSH-Px) activities and inhibited the formation of lipid peroxidized products in rats treated with $\mathrm{CCl}_{4}$.

Conclusion: The EPP and EPS have protective effects against liver fibrosis induced by $\mathrm{CCl}_{4}$, and its mechanisms might be associated with their antioxidant activity, the ability of decreasing the level of TGF- $\beta 1$ and inhibition of collagen synthesis.
\end{abstract}

Keywords: The extract of pomegranate peels, The extract of pomegranate seeds, Liver fibrosis, Oxidative stress

\section{Background}

Liver fibrosis which is a common feature of the majority of chronic liver diseases is considered as an important medical problem due to its high morbidity and mortality $[1,2]$. Hepatitis viral infections are the most common cause, and drug abuse, autoimmune

\footnotetext{
* Correspondence: zhaomingxitu@163.com; zwj@mail.xjtu.edu.cn 'Department of Pharmacology, Xi'an Jiaotong University Health Science Center, P.O. Box 77\#No.76 Yanta West Road, Xi'an 710061, People's Republic of China

Full list of author information is available at the end of the article
}

disorders, biliary obstruction and metabolic disorders due to mineral overload are also contributed to the disease $[3,4]$, which is characterized as excessive accumulation of collagen and extracellular matrix proteins within the perisinusoidal space [5, 6]. Advanced liver fibrosis could leads to cirrhosis and liver failure eventually. Now there is few effective medical treatments approaches for liver fibrosis [6].

The pathogenesis of liver fibrosis remains elusive. Oxidative stress is recognized as a fundamental factor in the pathological changes observed in various liver

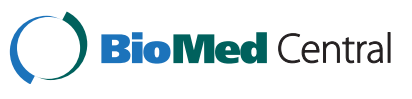

(c) 2015 Wei et al. Open Access This article is distributed under the terms of the Creative Commons Attribution 4.0 International License (http://creativecommons.org/licenses/by/4.0/), which permits unrestricted use, distribution, and reproduction in any medium, provided you give appropriate credit to the original author(s) and the source, provide a link to the Creative Commons license, and indicate if changes were made. The Creative Commons Public Domain Dedication waiver (http://creativecommons.org/publicdomain/zero/1.0/) applies to the data made available in this article, unless otherwise stated. 
diseases [7, 8]. Free radicals, formed as a result of oxidation, attack the unsaturated fatty acids of biomembranes, which results in peroxidation and destruction of protein and DNA, leading to various liver injuries [9]. Several lines of evidence have recently suggested that oxidative stress plays a pivotal role in the pathogenesis of liver fibrosis [10]. Antioxidants are effective for preventing liver fibrogenesis [11-13].

Pomegranate belongs to the Punicagranatum L., and is widely cultivated in India, Southeast Asia, Malaya, the East Indies, tropical Africa and China $[14,15]$. As in the earlier study, pomegranate had been used as an anthelmintic and antidiarrheal agent. Recently, the antioxidant activity of pomegranate is more and more being paid attention [16]. Pomegranate contains large amounts of polyphenols and flavonoid, so that the antioxidant capacity are obvious among in pomegranate fruit, juice and peel [17-20]. There is growing evidence that EPP have effective effect against liver fibrosis in rats. Experimental observations indicated that punicagranatum peel methanolic extract reversed thioacetamide-induced liver fibrosis, and significantly decreased the activity of liver enzymes, bilirubin and serum hepatocyte growth factor levels. These effects could be attributed to its antioxidant properties, antifibrotic and antiapoptotic activity [21]. Tokluet al. have also found that EPP prevents liver fibrosis in biliary-obstructed rats, and forecasted EPP's antioxidant and antifibrotic properties, may be of potential therapeutic value in protecting the liver from fibrosis and oxidative injury due to biliary obstruction [22]. However, the antifibrotic effect of EPS on chronic liver diseases has not been published in the literature. In this study, we aimed to investigate the effect of EPP and EPS on $\mathrm{CCl}_{4}$-induced liver fibrosis in rats and to propose its possible mechanism.

\section{Methods}

\section{Chemicals}

Carbon tetrachloride $\left(\mathrm{CCl}_{4}\right)$ was purchased from Sigma (St. Louis,MO, USA). Commercial kits for aspartate aminotransferase (AST), alanine aminotransferase (ALT), total bilirubin (T-Bil), malondialdehyde (MDA), glutathione peroxidase (GSH-Px), and superoxide dismutase (SOD), as well as hydroxyprolinewere purchased from Jiancheng Biotechnology Company (Nanjing, China). The hyaluronic acid (HA), Laminin (LN), and procollagen type III (PC III) radioimmunoassay kits were purchased from Beijing North Instirute of Biotechnology (Beijing, China). Transforming growth factor- $\beta 1$ (TGF- $\beta 1$ ) was purchased from Shanghai Huole Institute of Biotechnology (Shanghai,
China). Allother chemicals and reagents used in this study were of analyticalgrade.

The extracts of pomegranate peels and seeds preparation Fresh pomegranate fruits were collected in September to October, 2011 from a natural habitat in Shannxi, China. Then the pomegranate peels and seeds were artificially isolated and cleaned, air-dried. The dried pomegranate peels and seeds were grinded to coarse powder and passed through the 60 mesh screen, respectively. The above materials and methods were authenticated by Professor Qiang Wang who works at Department of Chinese Materia Medica Analysis, China Pharmaceutical University, Nanjing, where a voucher specimen has been deposited (2011-09).

The EPP and EPS were prepared following the method described previously with some modification [23]. The 3 kilogramme pomegranate peel powder and the 2 kilogramme pomegranate seed powder were extracted with $50 \%$ ethanol in triplicate at $85{ }^{\circ} \mathrm{C}$, respectively. The extracts were then filtered and evaporate under vacuum until dried. The dried EPP and EPS were stored in a refrigerator.

\section{Animals}

The forty male wistar rats aged 6-8 weeks old and weighed 180-200 g purchased from the Experimental Animal Center Jiaotong University. Rats were housed in plastic cages (five rats per cage) at $24{ }^{\circ} \mathrm{C}$ and $60 \%$ humidity with a $12 \mathrm{~h}-12 \mathrm{~h}$ light-dark cycle and ad libitum access to water and standard rat chow. The study protocol was approved by the Ethics committee of the Xi'an Jiaotong University Health Science Center. Animal handling and care was carried out throughout the experiment following international laboratory animal use and care guidelines (NIH publication no. 85-23, revised1996).

\section{Experimental model and drug treatment}

In this experiment, the rats were randomly divided into four groups, each of whom has ten rats. (1) Sham group (sham), in which rats were subcutaneously injected with vegetal oil without $\mathrm{CCl}_{4}(1 \mathrm{mg} / \mathrm{kg}$ body weight, twice a week for four weeks; (2) $\mathrm{CCl}_{4}$ group $\left(\mathrm{CCl}_{4}\right)$, in which rats were subcutaneously injected with $50 \% \mathrm{CCl}_{4}$ mixed with vegetal oil (1 mL/kg body weight) [24, 25]; (3) $\mathrm{CCl}_{4}$ $+\mathrm{EPP}$ group $\left(\mathrm{CCl}_{4}+\mathrm{EPP}\right)$, in which rats were administered with EPP (150 mg/kg body weight) intragastrically every day for 4 weeks at the same time subjected to $\mathrm{CCl}_{4}$ and (4) $\mathrm{CCl}_{4}+\mathrm{EPS}$ group $\left(\mathrm{CCl}_{4}+\mathrm{EPS}\right)$, in which rats were administered EPS (100 $\mathrm{mg} / \mathrm{kg}$ body weight) intragastrically every day for 4 weeks at the same time subjected to $\mathrm{CCl}_{4}$. At $24 \mathrm{~h}$ after the final injection of 
$\mathrm{CCl}_{4}$, all rats were anaesthetized with diethyl ether, and the blood samples were collected from the orbital veins. The serum samples were obtained by centrifugation of blood at $3000 \mathrm{rpm}$ for $15 \mathrm{~min}$ and were kept frozen at $-80{ }^{\circ} \mathrm{C}$ until assayed as described below. After the rats were killed, the livers and spleen were immediately removed, rinsed in ice-cold saline and weighed. A portion of each liver was fixed in $10 \%$ formalin for histological analyses, and the remaining tissues were stored at $-80{ }^{\circ} \mathrm{C}$ until required.

\section{Liver index and spleen index}

Relative weights of liver and spleen were expressed as the percentage of the body weight respectively.

\section{Biochemical metabolic parameters Assessment of liver function}

The serum activities of AST and ALT were evaluated by spectrophotometry using commercially available kits according to the manufacturer's instructions; The levels of HA, LN and PC III were determined using radioimmunoassay kits according to the manufacturer's instructions; TGF- $\beta 1$ level in serum was deternined by using rat enzyme-linked immunosorbent assay (ELISA) kit.

\section{Assessment of oxidative stress and enzymatic antioxidant status}

The tissue homogenates $(10 \%, \mathrm{w} / \mathrm{v})$ of livers were used in determination of MDA, SOD and GSH-Px levels according to the instructions.

\section{Assessment of collagen}

Liver collagen concentration was determined by measuring Hydroxyproline level according to the method described previously [1].

\section{Histological observation}

Rat livers were carefully isolated and fixed with $10 \%$ formalin solution for $24 \mathrm{~h}$. Fixed tissues were dehydrated and embedded in paraffin and then cut into $5 \mu \mathrm{m} \mathrm{sec-}$ tions with a Leica RM2135 (Leica, Bensheim, Germany) for staining. Sections were stained with Hematoxylineosin staining (HE) to observe liver injury, stained with Masson staining to detect collagen deposition and stained with Sirius red stain to measure the collagen content and type. The pathological changes were assessed and photographed with an Nikon, Japan microsco Liver fibrosis equipped with digital camera (Nikon, Japan) or polarization microscope (Nikon, Japan). was graded according to the following scoring system as following [26]: 0, no fibrosis, normal liver and absence of fibrosis; I, fibrosis present (collagen fiber present that extends from portal triad or central vein to peripheral region); II, mild fibrosis (mild collagen fiber present with extension without compartment formation); III, moderate fibrosis (moderate collagen fiber present with some pseudo lobe formation) and IV, severe fibrosis (severe collagen fiber present with thickening of the partial compartments and frequent pseudo lobe formation).

\section{Statistical analysis}

Quantitative data was expressed as the mean \pm S.D. The significance of the difference versus the $\mathrm{CCl}_{4}$ group was determined by a Student's $t$-test. A Mann-Whitney rank sum test was used for the analysis of degree of histopathological liver fibrosis. $P<0.05$ was considered to be statistically significant.

\section{Results}

The effects of extracts on body weight, liver and spleen index

The effects of EPP and EPS on the rats' body weight were evaluated. Rats were subcutaneously injected with $\mathrm{CCl}_{4}$, twice a week for four weeks. The body weight gain were statistically reduced compared with the sham group $(92.74 \pm 18.61$ vs. $141.09 \pm 12.72 \mathrm{~g}, P<0.05, n=10)$. Pretreatment with either EPP or EPS increase the final body weights of rats to $308.22 \pm 19.44 \mathrm{~g}$ and $309.10 \pm 20.72 \mathrm{~g}$ respectively. Their body weight gain were higher than $\mathrm{CCl}_{4}$ group $(128.30 \pm 24.50$ and $125.10 \pm 22.09 \mathrm{~g}$, vs. $\mathrm{CCl}_{4}$ group, $P<0.05, n=10$, Table 1 ).

Subsequently, the liver and spleen index were calculated as the percentage of the body weight. The results showed that the liver and spleen index in $\mathrm{CCl}_{4}$ group were significantly higher than the sham group (5.97 \pm 0.49 and $0.50 \pm 0.055 \%$ vs. $2.75 \pm 0.42$ and $0.25 \pm$ $0.035 \%, P<0.05, n=10)$. While fed with the EPP and EPS, these indexes were significantly lower than the $\mathrm{CCl}_{4}$ group (EPP: $3.58 \pm 0.63$ and $0.36 \pm 0.055 \%$; EPS: $3.55 \pm 0.55$ and $0.35 \pm 0.039 \%$, vs. $\mathrm{CCl}_{4}$ group, $P<0.05$, $n=10$, Table 1 ).

\section{The effects of extracts on liver function}

The significantly higher levels of ALT, AST and T-Bil in the serum of the rats in the $\mathrm{CCl}_{4}$ group were exhibited than that of the sham group (ALT: 121.17 \pm 21.24 vs. $33.70 \pm 6.04 \mathrm{U} / \mathrm{L} ;$ AST: $169.20 \pm 22.15$ vs. $55.31 \pm 6.22 \mathrm{U} / \mathrm{L}$; T-Bil: $9.25 \pm 0.66$ vs. $3.07 \pm 0.98 \mathrm{~mol} /$ L, respectively; $P<0.01, n=10)$. EPP and EPS treatment efficiently reduced the ALT level to $88.50 \pm$ 11.62 and $89.62 \pm 11.01 \mathrm{U} / \mathrm{L}(P<0.05, n=10$, Fig. 1a), decreased the AST to $124.90 \pm 24.90$ and $126.33 \pm$ 18.84 U/L $(P<0.05, n=10$, Fig. $1 \mathrm{~b})$, and also significantly suppressed $\mathrm{CCl}_{4}$-induced increase in T-Bil level $(4.73 \pm 1.09$ and $5.51 \pm 1.20 \mathrm{~mol} / \mathrm{L}, P<0.05, n=10$, Fig. 1c). The result indicated that the EPP and EPS had protective effects against liver injuries in rats injected with $\mathrm{CCl}_{4}$. 
Table 1 Initial body weight, final body weight, body weight gain, liver index and spleen index in differente experimental groups

\begin{tabular}{|c|c|c|c|c|c|}
\hline \multirow[t]{2}{*}{ Groups } & \multicolumn{2}{|l|}{ Body weight (g) } & \multirow{2}{*}{$\begin{array}{l}\text { Body weight } \\
\text { gain (g) }\end{array}$} & \multirow{2}{*}{$\begin{array}{l}\text { Liver index } \\
(\%)\end{array}$} & \multirow{2}{*}{$\begin{array}{l}\text { Spleen } \\
\text { index (\%) }\end{array}$} \\
\hline & Initial & Final & & & \\
\hline Sham & $180.41 \pm 14.31$ & $321.50 \pm 18.49$ & $141.09 \pm 12.72$ & $2.75 \pm 0.42$ & $0.25 \pm 0.035$ \\
\hline $\mathrm{CCl}_{4}$ & $179.66 \pm 10.10$ & $272.40 \pm 21.03$ & $92.74 \pm 18.61^{*}$ & $5.97 \pm 0.49^{*}$ & $0.50 \pm 0.055^{*}$ \\
\hline $\mathrm{CCl}_{4}+\mathrm{EPP}$ & $180.82 \pm 9.28$ & $308.22 \pm 19.44$ & $128.30 \pm 24.50^{\#}$ & $3.58 \pm 0.63^{\#}$ & $0.36 \pm 0.055^{\#}$ \\
\hline $\mathrm{CCl}_{4}+\mathrm{EPS}$ & $184.00 \pm 10.98$ & $309.10 \pm 20.72$ & $125.10 \pm 22.09^{\#}$ & $3.55 \pm 0.55^{\#}$ & $0.35 \pm 0.039^{\#}$ \\
\hline
\end{tabular}

EPP $(150 \mathrm{mg} / \mathrm{kg})$ and EPS $(100 \mathrm{mg} / \mathrm{kg})$ were administered orally for 4 weeks. The values are expressed as the mean \pm S.D. $(n=10) . * P<0.05$, compared with the sham group, ${ }^{\#} P<0.05$, compared with the $\mathrm{CCl}_{4}$ group

\section{The effects of extracts on the microstructure of liver}

The effects of EPP and EPS on the microstructure changes of liver were shown in Fig. 2. The results of HE staining indicated that $\mathrm{CCl}_{4}$ administration presented extensive changes in liver morphology, including marked enlarged areas of hepatocellular degeneration and infiltration inflammatory cells. No histological abnormalities were observed in sham group. EPP and EPS treatment significantly alleviated the degree of liver injury.

The EPP and EPS attenuates $\mathrm{CCl}_{4}$-induced liver fibrosis Further, the effects of EPP and EPS on the markers of liver fibrosis were examined. As shown in Fig. 3a, the level of TGF- $\beta 1$ in $\mathrm{CCl}_{4}$ group was elevated significantly compared to that of the sham group (38.27 \pm 5.37 vs. $11.14 \pm 1.39 \mu \mathrm{g} / \mathrm{L}, P<0.01, n=10)$. EPP and EPS significantly decreased the TGF- $\beta 1$ level in serum compared to that of the $\mathrm{CCl}_{4}$ group $(25.00 \pm 2.67$ and $26.29 \pm 2.95 \mu \mathrm{g} /$ $\mathrm{L}, P<0.05, n=10)$.

Hydroxyproline content in liver and serum levels of HA, LN and PC III as the indexes of liver fibrosis were tested. It is shown that $\mathrm{CCl}_{4}$ significantly increased hydroxyproline, HA, LN and PC III compare with that of the sham group (hydroxyproline: $2.81 \pm 0.33$ vs. $1.13 \pm$ $0.18 \mathrm{mg} / \mathrm{g} ; \mathrm{HA}: 239.38 \pm 32.80$ vs. $92.08 \pm 22.77 \mu \mathrm{g} / \mathrm{L}$; LN: $253.85 \pm 36.47$ vs. $99.54 \pm 24.63 \mu \mathrm{g} / \mathrm{L}$ and PC III: $256.26 \pm 31.40$ vs. $92.17 \pm 18.48 \mu \mathrm{g} / \mathrm{L}, P<0.01, n=10)$.
EPP and EPS had potential for the reduction of hydroxyproline, $\mathrm{HA}, \mathrm{LN}$ and PC III level that increased by $\mathrm{CCl}_{4}$. The final values were hydroxyproline: $2.12 \pm 0.28$ and $2.17 \pm 0.30 \mathrm{mg} / \mathrm{g} ; \quad \mathrm{HA}: 168.64 \pm 26.61$ and $170.98 \pm$ $31.11 \mu \mathrm{g} / \mathrm{L} ; \mathrm{LN}: 183.77 \pm 31.12$ and $186.17 \pm 31.95 \mu \mathrm{g} / \mathrm{L}$; PC III: $165.77 \pm 19.30$ and $174.30 \pm 24.93 \mu \mathrm{g} / \mathrm{L}(P<0.05$, $n=10$, fig B-E).

\section{The effects of extracts on liver fibrosis histological examination}

Liver fibrosis was evaluated histologically using Masson staining and Sirius red staining in the different groups. The Masson staining showed that the normal hepatic lobules in $\mathrm{CCl}_{4}$ group were disappeared, collagen was deposited and pseudo lobule was formed. Treatment with EPP and EPS obviously alleviated the collagen deposition. Fig. 4b showed that treatment with EPP and EPS significantly lower the graded of fibrosis as compared to $\mathrm{CCl}_{4}$ group $(P<0.01, P<0.05, n=10)$.

Sirius red stains collagen red on a pale yellow background in brightfield microscope, whereas under polarization microscope the typeI collagen appears bright orange-red and the type III collagen appears bright yellowgreen. Sirius red staining showed that in $\mathrm{CCl}_{4}$ group, type I and III collagen were more than that of the sham group, and treatment with EPP and EPS could effectively against the increase in type I and III collagen induced by $\mathrm{CCl}_{4}$ $(P<0.01, P<0.05, n=10$, Fig. 4c).
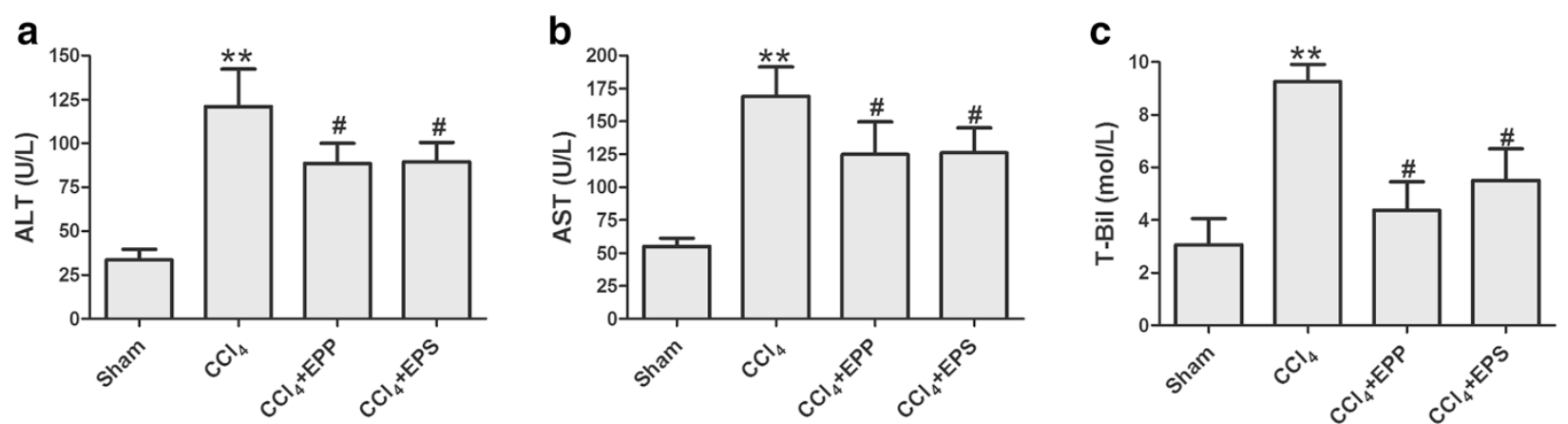

Fig. 1 Effects of EPP and EPS on serum of ALT (a), AST (b) and T-Bil (c) after $C_{C l}$ injury. ${ }^{* *} P<0.01$, vs. sham group; ${ }^{*} P<0.05$, vs. CCl 4 group; $n=10$ in each group; values are mean \pm S.D 


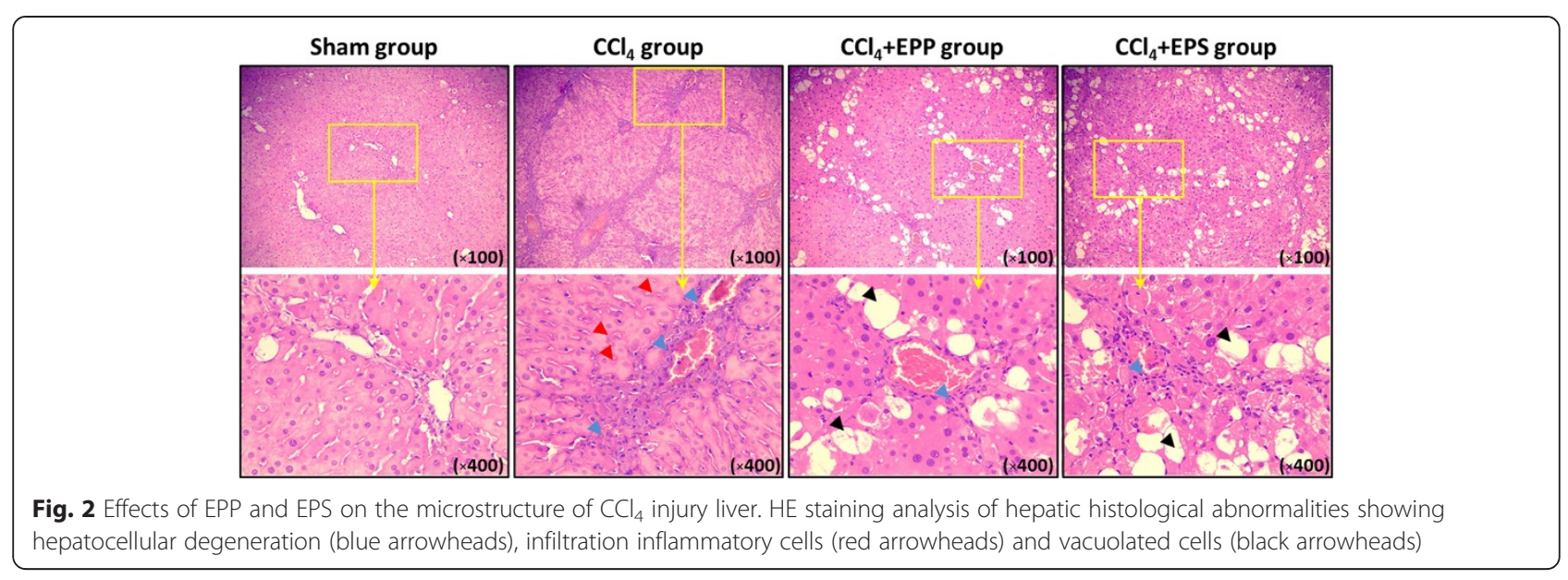

The effects of extracts on hepatic MDA, SOD and GSH-Px activities

As expected, the treatment with EPP and EPS also showed effective anti-oxygenation in $\mathrm{CCl}_{4}$ injury rats. MDA levels, and the end product of lipid peroxidation, were significantly higher in the $\mathrm{CCl}_{4}$ group than in the sham-operated group $(P<0.05)$. In the EPP and EPS treated groups, hepatic MDA levels were markedly decreased compared with that of the $\mathrm{CCl}_{4}$ group (EPP: $50.21 \pm 10.23$ vs. $71.10 \pm 12.63 \mu \mathrm{mol} / \mathrm{g}$; EPS: $50.84 \pm$ $11.05 \mu \mathrm{mol} / \mathrm{g}, P<0.05, n=10$, Fig. 5a).
Meanwhile, thehepatic SOD and GSH-Pxactivities were lower in the $\mathrm{CCl}_{4}$ group than in the sham-operated group $(P<0.01)$. EPP and EPS treatment both efficiently increased the SOD activities from $133.47 \pm 28.29 \mathrm{U} / \mathrm{mg}$ in the $\mathrm{CCl}_{4}$ group to $185.72 \pm 30.05 \mathrm{U} / \mathrm{mg}$ in the EPP group and $187.94 \pm 21.38 \mathrm{U} / \mathrm{mg}$ in the EPS group $(P<0.05, n=10$, Fig. 5b). They also efficiently increased the GSH-Pxactivities from $252.07 \pm 39.39 \mathrm{U} / \mathrm{mg}$ in the $\mathrm{CCl}_{4}$ group to $355.73 \pm 41.88 \mathrm{U} / \mathrm{mg}$ in the EPP group and $349.47 \pm 40.10 \mathrm{U} / \mathrm{mg}$ in the EPS group $(P<0.05, n=10$, Fig. 5c).
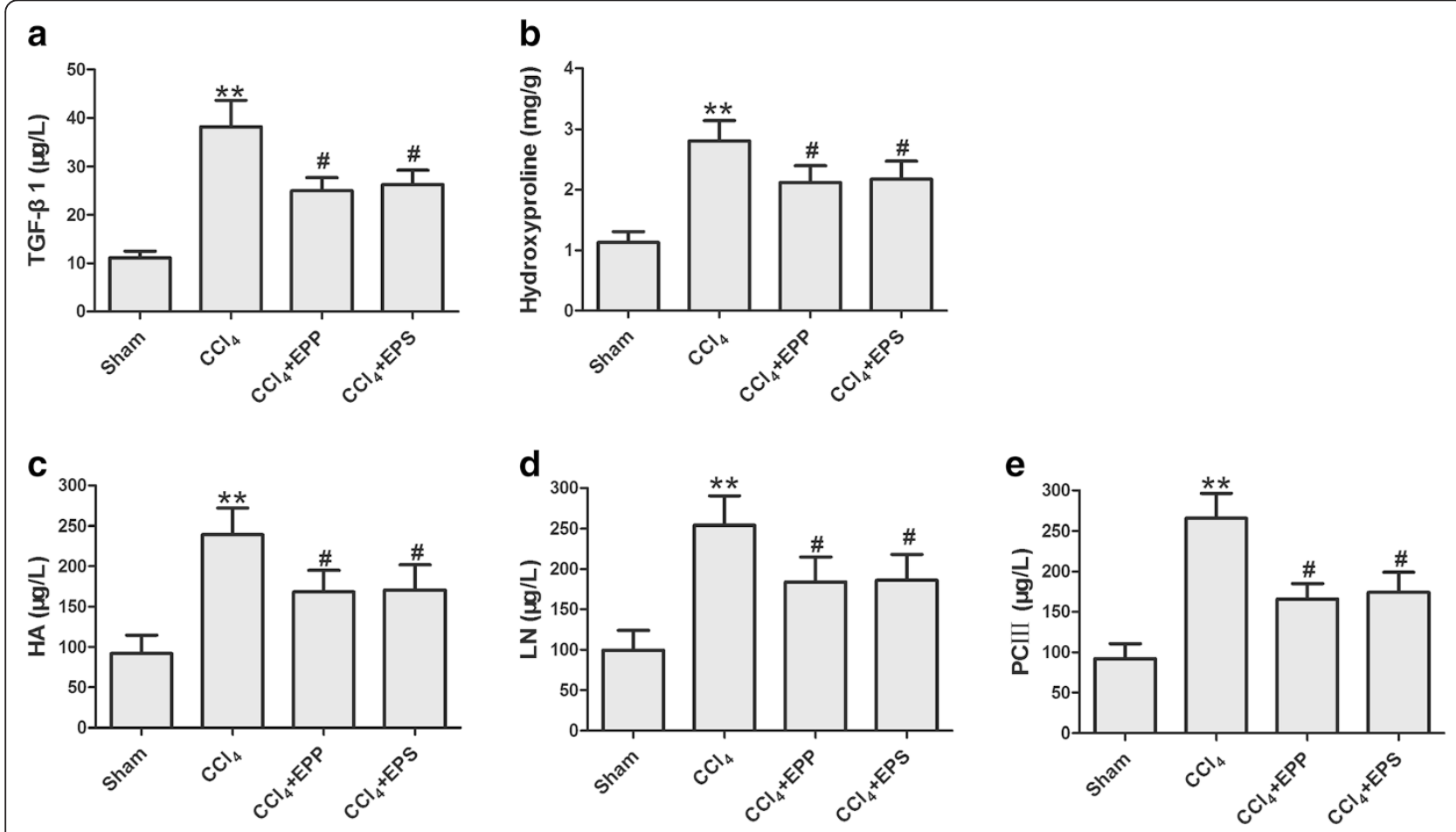

Fig. 3 Effects of EPP and EPS onserum of TGF- $\beta 1$ (a), HA (c), LN (d), PC III (e) and liver of hydroxyproline (b) after $C \mathrm{Cl}_{4}$ injury. ${ }^{* *} P<0.01$, vs. sham group; ${ }^{\#} P<0.05$, vs. $C C_{4}$ group; $n=10$ in each group; values are mean \pm S.D 


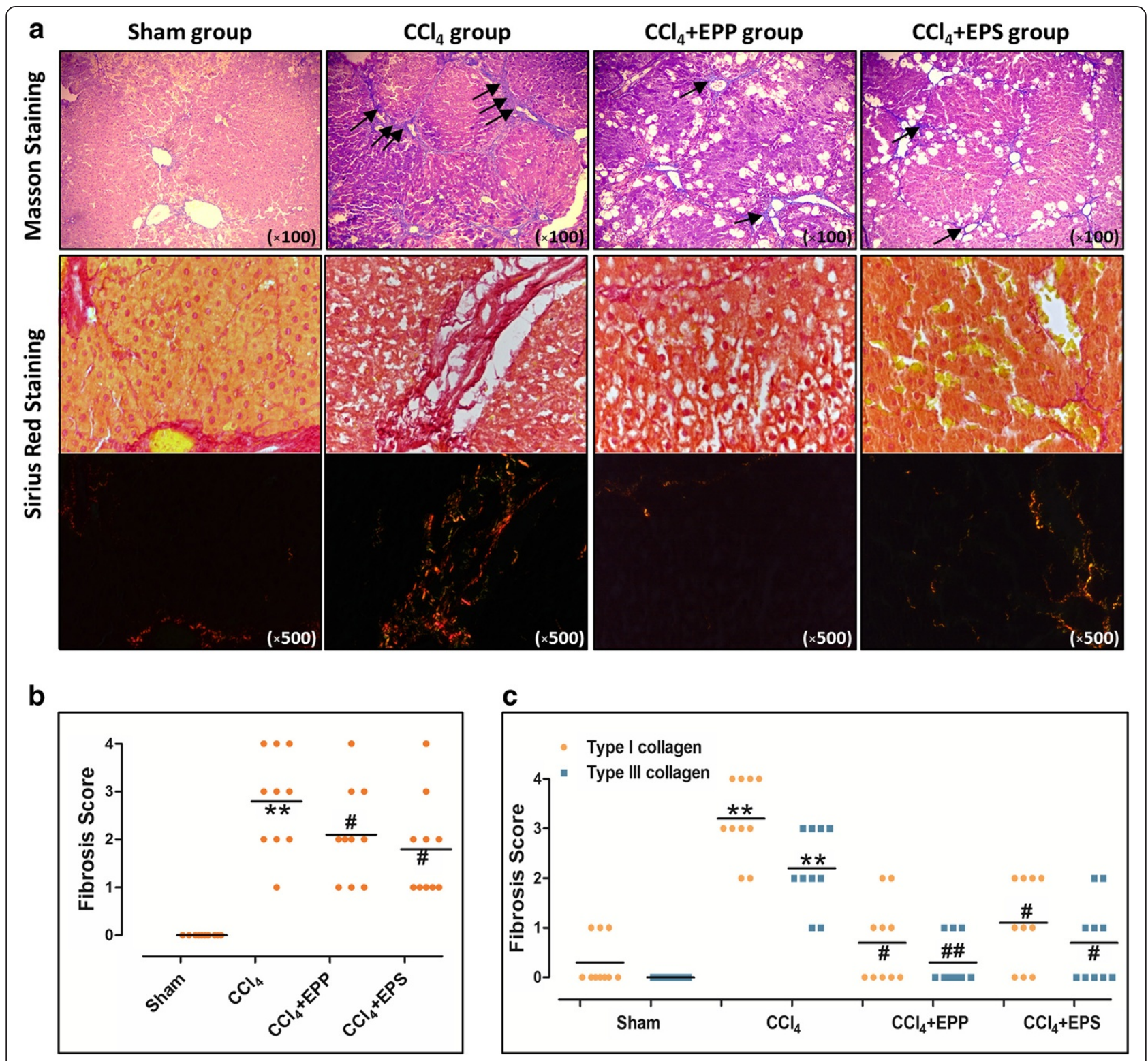

Fig. 4 Effect of EPP and EPS on histological morphology of fibrosis rat liver with Masson and Sirius red staining. a: Masson and Sirius red staining analysis of hepatic fibrosis (arrows); $\mathbf{b}$ : the graded of fibrosis with Masson staining; c: the type and graded of fibrosis with Sirius red staining. ${ }^{* *} P<0.01$, vs. sham group; ${ }^{\# \#} P<0.01,{ }^{\#} P<0.05$, vs. $C C_{4}$ group; $n=10$ in each group; values are mean \pm S.D

\section{Discussion}

The aim of this study is to evaluate the protective effects of the extracts of the pomegranate peels and seeds against liver fibrosis induced by $\mathrm{CCl}_{4}$ in rats. The study showed that EPP and EPS treatment appeared to be beneficial in this animal model of $\mathrm{CCl}_{4}$ injury in terms of reduced liver index and spleen index, improved liver function, and inhibited the development of hepatic fibrosis rats. These protective effects may depend on decreased MDA levels and increase SOD and GSH-Px activities, which implied anti-oxygenation activity may be the possible mechanism of EPP and EPS in abrogating liver fibrosis.

$\mathrm{CCl}_{4}$ treatment is frequently used in rats to produce an experimental model to study liver fibrosis [27, 28]. In the present study, liver fibrosis was successfully induced by subcutaneous injection of $50 \% \mathrm{CCl}_{4}$ for a period of 4 weeks. The histological results showed that the normal structure of lobules was destroyed and pseudolobules formed. Moreover, the increased hydroxyproline content in liver and serum HA, LN and PC III also confirmed the liver fibrosis in rats. 

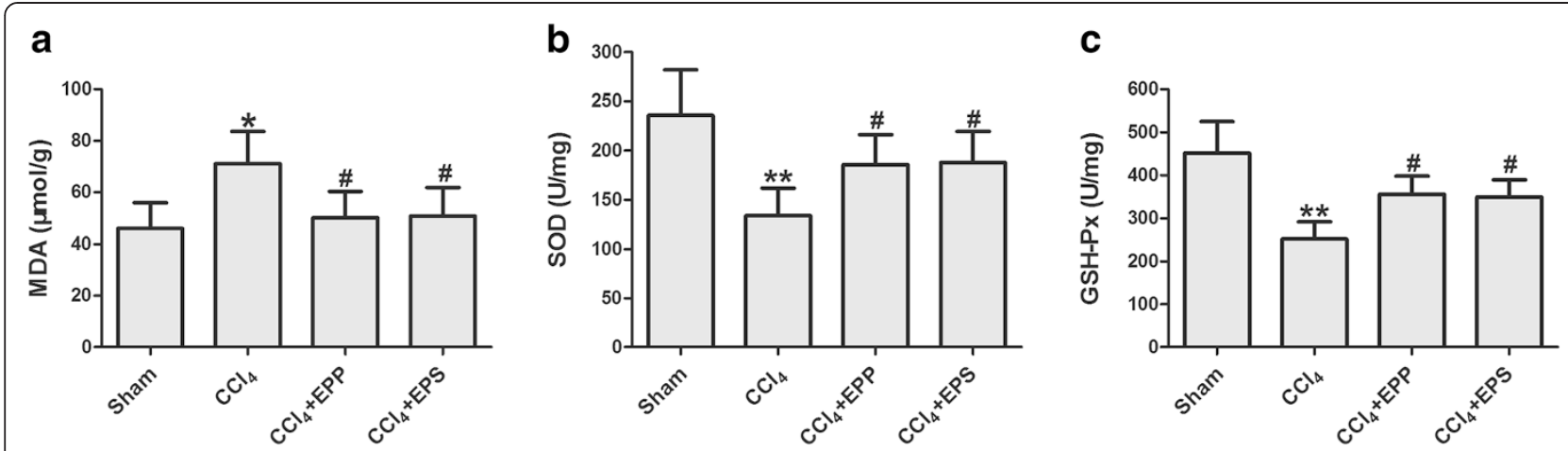

Fig. 5 Effects of EPP and EPS on MDA level (a), SOD (b) and GSH-Px (c) activities in liver homogenates of liver fibrosis rats. ${ }^{*} P<0.01$, ${ }^{*} P<0.05$ vs. sham group; ${ }^{\#} P<0.05$, vs. $\mathrm{CCl}_{4}$ group; $n=10$ in each group; values are mean \pm S.D

The increased levels of aminotransferases are the results of leakage from damaged hepatic cells and are used as markers of liver injury [29]. It was shown in this study that abnormal aminotransferase activity was noted in rats injected with $\mathrm{CCl}_{4}$ and were decreased by administration of the EPP and EPS. These results provided evidence that the EPP and EPS are able to improve hepatic steatosis in rats without obvious hepatotoxicity. The hepato protective effects of EPP and EPS were further evidenced by marked improvement in the histopathological examination.

Proteins HA, LN and PC III are important biomarkers of hepatic fibrogenesis [30,31]. Hydroxyproline in liver is an important index whose level reflects the amount of collagen and therefore it can be used to determine the extent of fibrosis [32]. Thus, HA, LN, PC III and hydroxyproline are important indexes to appraisal liver fibrosis. The result in this study showed that EPP and EPS could significantly decrease HA, LN and PC III in serum and hydroxyproline content in liver, which suggested that EPP and EPS can inhibit collagen deposition in liver.

Being recognized as a major profibrogenic cytokine in the progression of liver fibrosis, TGF- $\beta 1$ is responsible for hepatic stellate cells (HSCs) activation and migration which is supposed to be the central event of liver fibrosis $[33,34]$. It has been reported that anti-TGF- $\beta 1$ antibody ameliorated concanavalin Ainduced liver fibrosis, while over-expression of TGF$\beta 1$ in transgenic mice resulted in the acceleration of liver fibrosis progression $[35,36]$. The overexpression of TGF- $\beta 1$ has been correlated with the degree of fibrosis in both animal models and human diseases. The results in this study showed that EPP and EPS decreased the serum levels of TGF- $\beta 1$, which suggested that these extracts may be associated with the regulation of cytokine release.

It has been proved that oxidative stress plays an important role in the generation of $\mathrm{CCl}_{4}$-induced liver fibrosis [37-39]. $\mathrm{CCl}_{4}$ can be metabolized by cytochrome P450 in liver cells after being injected into rats, and eventually yield the trichloromethyl-free radical. These compounds trigger a cascade of reactions and lipid peroxidation, which lead to cell injury and chronic liver injury with the result of liver fibrosis [40]. MDA is the main product of lipid peroxidation and its concentration is generally presented as the total level of lipid peroxidation products [41]. SOD and GSH-Px are key enzymes in antioxidant defense system, and they can catalyze the transformation of hydrogen peroxide into water [42-44]. The results in this study demonstrated that $\mathrm{CCl}_{4}$ led to increases of MDA levels and decreases of SOD and GSH-Px levels in the liver. Administration of EPP and EPS increased SOD and GSH-Px activity, while depressed MDA production in hepatic tissues in rats treated with $\mathrm{CCl}_{4}$. These results indicated that the protective effects of EPP and EPS on liver fibrosis were partly due to their antioxidant activities.

Additionally, this study showed that EPP and EPS affected the protective action on liver injury and antioxidant state. These resulte are probably attributed to its phenolic compounds and linolenic acid contained in this fruit. EPP mainly contain total phenolics, including mainly hydrolyzable tannins (ellagitannins), such as oligomers and punicalagin/punicalin. Nevertheless, EPS mainly contain fatty acids (eg. punicic acid, linolenic acid isomers, linoleic, palmitic and stearic, et al.), no phenolics are present [22]. The antioxidant activity of phenolics and linolenic acid are mainly due to their redox properties, which allow them to act as reducing agents, hydrogen donors, singlet oxygen quenchers, and metal chelators $[22,45]$.

\section{Conclusions}

In conclusion, pomegranate is a high nutritious and desirable fruit with rich bioactive profile. Because of its beneficial physiological activities, the consumption of pomegranate has grown tremendously. The present 
study showed that pomegranate peels and seeds have preventive effects against liver fibrosis. The main mechanisms of the effects might be related to its antioxidant activity, decreased the level of TGF- $\beta 1$ and inhibition of collagen synthesis. However, further studies are required.

\section{Competing interests}

The authors declare that they have no competing interests.

\section{Authors' contributions}

Study concept and design: XLW, MZ and WJZ. Data collection: XLW, RTF, YHY, GXR and ALL. Statistical analysis: XLW, MZ, XYB and WJZ. Analysis and interpretation of data: XLW and MZ. Drafting of the manuscript: XLW. Critical revision of the manuscript for important intellectual content: $M Z$ and WJZ. Study supervision: MZ and WJZ. All authors read and approved the final manuscript.

\section{Acknowledgements}

This work is supported by the National Natural Science Foundation of China (Major International Joint Research Project, No. 81120108002 ; General Project, No. 81402924), the Specialized Research Fund for the Doctoral Program of HigherEducation (No. 20130201130008), the China Postdoctoral Science Foundation (No.2013 M542359) and the Postdoctoral Science Foundation of Shaanxi Province.

\section{Author details}

'Department of Pharmacology, Xi'an Jiaotong University Health Science Center, P.O. Box 77\#No.76 Yanta West Road, Xi'an 710061, People's Republic of China. ${ }^{2}$ Department of Pharmacy, Xi'an Chest Hospital, Xi'an 710061, People's Republic of China. ${ }^{3}$ Department of Gastroenterology, The 451 Hospital of the Chinese People's Liberation Army, Xi'an 710054, People's Republic of China. ${ }^{4}$ Department of pediatrics, The First Affiliated Hospital of Xi'an Jiaotong University, Xi'an 710061, People's Republic of China.

Received: 17 March 2015 Accepted: 14 October 2015

Published online: 27 October 2015

\section{References}

1. Sun WY, Wei W, Wu L, Gui SY, Wang H. Effects and mechanisms of extract from Paeonia lactiflora and Astragalus membranaceus on liver fibrosis induced by carbon tetrachloride in rats. J Ethnopharmacol. 2007;112:514-23.

2. Huang $X$, Wang $X, L v Y, X u L$, Lin J, Diao Y. Protection effect of kallistatin on carbon tetrachloride-induced liver fibrosis in rats via antioxidative stress. Plos ONE. 2014;9, e88498.

3. Friedman SL. Liver fibrosis - from bench to bedside. J Hepatol. 2003;38 Suppl 1:S38-53.

4. Kisseleva T, Brenner DA. Hepatic stellate cells and the reversal of fibrosis. J Gastroen Hepatol. 2006;21:584-7.

5. Dai LJ, Li HY, Guan LX, Ritchie G, Zhou JX. The therapeutic potential of bone marrow-derived mesenchymal stem cells on hepatic cirrhosis. Stem Cell Res. 2009;2:16-25.

6. Sun WY, Wang L, Liu H, Li X, Wei W. A standardized extract from Paeonia lactiflora and Astragalus membranaceus attenuates liver fibrosis induced by porcine serum in rats. Int J Mol Med. 2012;29:491-8.

7. Cederbaum Al, Lu Y, Wu D. Role of oxidative stress in alcohol-induced liver injury. Arch Toxicol. 2009:83:519-48.

8. Aboutwerat A, Pemberton PW, Smith A, Burrows PC, McMahon RF, Jain SK, et al. Oxidant stress is a significant feature of primary biliary cirrhosis. Biochim Biophys Acta. 2003;1637:142-50

9. Sastre J, Serviddio G, Pereda J, Minana JB, Arduini A, Vendemiale G, et al. Mitochondrial function in liver disease. Front Biosci. 2007:12:1200-9.

10. Poli G. Pathogenesis of liver fibrosis: role of oxidative stress. Mol Aspects Med. 2000;21:49-98

11. Lee TY, Wang GJ, Chiu JH, Lin HC. Long-term administration of Salvia miltiorrhiza ameliorates carbon tetrachloride-induced hepatic fibrosis in rats. J Pharm Pharmacol. 2003;55:1561-8.

12. Vendemiale G, Grattagliano I, Caruso ML, Serviddio G, Valentini AM, Pirrelli $M$, et al. Increased oxidative stress in dimethylnitrosamine-induced liver fibrosis in the rat: effect of $\mathrm{N}$-acetylcysteine and interferon-alpha. Toxicol Appl Pharmacol. 2001;175:130-9.
13. Wasser $\mathrm{S}$, Ho JM, Ang HK, Tan CE. Salvia miltiorrhiza reduces experimentallyinduced hepatic fibrosis in rats. J Hepatol. 1998;29:760-71.

14. Elfalleh $W$, Ying $M$, Nasri $N$, Sheng-Hua $H$, Guasmi F, Ferchichi A. Fatty acids from Tunisian and Chinese pomegranate (Punica granatum L.) seeds. Int J Food Sci Nutr. 2011;62:200-6.

15. Fischer UA, Carle R, Kammerer DR. Identification and quantification of phenolic compounds from pomegranate (Punica granatum L.) peel, mesocarp, aril and differently produced juices by HPLC-DAD-ESI/MS(n). Food Chem. 2011;127:807-21.

16. Singh RP, Chidambara MK, Jayaprakasha GK. Studies on the antioxidant activity of pomegranate (Punica granatum) peel and seed extracts using in vitro models. J Agric Food Chem. 2002;50:81-6.

17. Aviram M, Dornfeld L. Pomegranate juice consumption inhibits serum angiotensin converting enzyme activity and reduces systolic blood pressure. Atherosclerosis. 2001;158:195-8.

18. Seeram NP, Adams $L S$, Henning SM, Niu Y, Zhang $Y$, Nair MG, et al. In vitro antiproliferative, apoptotic and antioxidant activities of punicalagin, ellagic acid and a total pomegranate tannin extract are enhanced in combination with other polyphenols as found in pomegranate juice. J Nutr Biochem. 2005;16:360-7.

19. Gomez-Caravaca AM, Verardo V, Toselli M, Segura-Carretero A, FernandezGutierrez A, Caboni MF. Determination of the major phenolic compounds in pomegranate juices by HPLC-DAD-ESI-MS. J Agric Food Chem. 2013;61:5328-37.

20. Aviram M, Volkova N, Coleman R, Dreher M, Reddy MK, Ferreira D, et al. Pomegranate phenolics from the peels, arils, and flowers are antiatherogenic: studies in vivo in atherosclerotic apolipoprotein e-deficient $\left(E^{0}\right)$ mice and in vitro in cultured macrophages and lipoproteins. J Agric Food Chem. 2008:56:1148-57.

21. Salwe KJ, Sachdev DO, Bahurupi Y, Kumarappan M. Evaluation of antidiabetic, hypolipedimic and antioxidant activity of hydroalcoholic extract of leaves and fruit peel of Punicagranatum in male Wistar albino rats. J Nat SciBiol Med. 2015;6:56-62.

22. Sadeghipour A, Eidi M, IlchizadehKavgani A, Ghahramani R, Shahabzadeh S, Anissian A. Lipid lowering effect of punicagranatum L. Peel in high lipid diet Fed male rats. Evid Based Complement Alternat Med. 2014;2014:432650.

23. Gozlekci S, Saracoglu O, Onursal E, Ozgen M. Total phenolic distribution of juice, peel, and seed extracts of four pomegranate cultivars. Pharmacogn Mag. 2011;7:161-4

24. Iredale JP, Benyon RC, Pickering J, McCullen M, Northrop M, Pawley S, et al. Mechanisms of spontaneous resolution of rat liver fibrosis. Hepatic stellate cell apoptosis and reduced hepatic expression of metalloproteinase inhibitors. J Clin Invest. 1998;102:538-49.

25. Yang $Y$, Nemoto EM, Harvey SA, Subbotin VM, Gandhi CR. Increased hepatic platelet activating factor (PAF) and PAF receptors in carbon tetrachloride induced liver cirrhosis. Gut. 2004;53:877-83.

26. Li C, Luo J, Li L, Cheng M, Huang N, Liu J, et al. The collagenolytic effects of the traditional Chinese medicine preparation, Han-Dan-Gan-Le, contribute to reversal of chemical-induced liver fibrosis in rats. Life Sci. 2003:72:1563-71.

27. Safer AM, Afzal M, Nomani A, Sosamma O, Mousa SA. Curative propensity of green tea extract towards hepatic fibrosis induced by CCI(4): A histopathological study. Exp Ther Med. 2012;3:781-6.

28. Fan W, Shi B, Wei H, Ma X, He X, Feng K. Gamma-aminobutyric acid B receptor improves carbon tetrachloride-induced liver fibrosis in rats. Dig Dis Sci. 2013:58:1909-15.

29. Giannini EG, Testa R, Savarino V. Liver enzyme alteration: a guide for clinicians. CMAJ. 2005;172:367-79.

30. Kim MY, Baik SK, Jang YO, Suk KT, Kim JW, Kim HS, et al. Serum hyaluronic acid level: correlation with quantitative measurement of hepatic fibrosis in a cirrhotic rat model. Korean J Hepatol. 2008;14:159-67.

31. Qiu W, Guo K, Yi L, Gong Y, Huang L, Zhong W. Resolvin E1 reduces hepatic fibrosis in mice with infection. Exp Ther Med. 2014;7:1481-5.

32. Dang SS, Wang BF, Cheng YA, Song P, Liu ZG, Li ZF. Inhibitory effects of saikosaponin-d on CCl4-induced hepatic fibrogenesis in rats. World J Gastroenterol. 2007;13:557-63.

33. Choi YJ, Kim DH, Kim SJ, Kim J, Jeong SI, Chung CH, et al. Decursin attenuates hepatic fibrogenesis through interrupting TGF-beta-mediated $\operatorname{NAD}(P) H$ oxidase activation and Smad signaling in vivo and in vitro. Life Sci. 2014;108:94-103. 
34. Dooley S, Ten DP. TGF-beta in progression of liver disease. Cell Tissue Res. 2012;347:245-56

35. Kimura K, Ando K, Ohnishi H, Ishikawa T, Kakumu S, Takemura M, et al. Immunopathogenesis of hepatic fibrosis in chronic liver injury induced by repeatedly administered concanavalin A. Int Immunol. 1999;11:1491-500.

36. Rachfal AW, Brigstock DR. Connective tissue growth factor (CTGF/CCN2) in hepatic fibrosis. Hepatol Res. 2003;26:1-9.

37. Luckey SW, Petersen DR. Activation of Kupffer cells during the course of carbon tetrachloride-induced liver injury and fibrosis in rats. Exp Mol Pathol. 2001;71:226-40

38. Hernandez-Munoz R, Diaz-Munoz M, Lopez V, Lopez-Barrera F, Yanez L, Vidrio $S$, et al. Balance between oxidative damage and proliferative potential in an experimental rat model of CCl4-induced cirrhosis: protective role of adenosine administration. Hepatology. 1997;26:1100-10.

39. Muriel P, Escobar Y. Kupffer cells are responsible for liver cirrhosis induced by carbon tetrachloride. J Appl Toxicol. 2003;23:103-8.

40. Wasser S, Tan CE. Experimental models of hepatic fibrosis in the rat. Ann Acad Med Singapore. 1999;28:109-11.

41. Drewa G, Krzyzynska-Malinowska E, Wozniak A, Protas-Drozd F, MilaKierzenkowska C, Rozwodowska M, et al. Activity of superoxide dismutase and catalase and the level of lipid peroxidation products reactive with TBA in patients with psoriasis. Med Sci Monit. 2002;8:R338-43.

42. Ballatori N, Krance SM, Notenboom S, Shi S, Tieu K, Hammond CL. Glutathione dysregulation and the etiology and progression of human diseases. Biol Chem. 2009;390:191-214.

43. Yin YY, Li WP, Gong HL, Zhu FF, Li WZ, Wu GC. Protective effect of astragaloside on focal cerebral ischemia/reperfusion injury in rats. Am J Chin Med. 2010;38:517-27.

44. Liochev SI, Fridovich I. Mechanism of the peroxidase activity of $\mathrm{Cu}, \mathrm{Zn}$ superoxide dismutase. Free Radic Biol Med. 2010;48:1565-9.

45. Rice-Evans CA, Miller NJ, Bolwell PG, Bramley PM, Pridham JB. The relative antioxidant activities of plant-derived polyphenolic flavonoids. Free Radic Res. 1995;22:375-83.

\section{Submit your next manuscript to BioMed Central and take full advantage of:}

- Convenient online submission

- Thorough peer review

- No space constraints or color figure charges

- Immediate publication on acceptance

- Inclusion in PubMed, CAS, Scopus and Google Scholar

- Research which is freely available for redistribution 